Conclusion: Women with IIM reported significantly impaired sexual function and sexual quality of life compared to age-matched healthy controls. Worse scores in IIM were associated with disease activity, physical activity, fatigue, depression and quality of life.

Acknowledgments: Supported by MHCR 023728, SVV 260373 and GAUK 1578119.

Disclosure of Interests: Barbora Heřmánková: None declared, Maja Špiritović: None declared, Sabina Oreska: None declared, Hana Štorkánová: None declared, Martin Klein: None declared, Karel Pavelka Consultant of: Abbvie, MSD, BMS, Egis, Roche, UCB, Medac, Pfizer, Biogen, Speakers bureau: Abbvie, MSD, BMS, Egis, Roche, UCB, Medac, Pfizer, Biogen, Ladislav Šenolt: None declared, Heřman Mann: None declared, Jiří Vencovský: None declared, Michal Tomčík: None declared

DOI: 10.1136/annrheumdis-2020-eular.3685

\section{SAT0628-HPR “IT IS THE NEVER ENDING QUEST, HOW TO MOTIVATE PEOPLE”' - HEALTH PROFESSIONALS' PERSPECTIVES ON SUPPORTING PHYSICAL ACTIVITY MAINTENANCE IN THOSE LIVING WITH AXIAL SPONDYLOARTHRITIS}

T. Ingram ${ }^{1,2}$, P. Rouse ${ }^{1}$, M. Standage ${ }^{1}$, R. Sengupta ${ }^{2,3} \cdot{ }^{1}$ University of Bath, Department for Health, Bath, United Kingdom; ${ }^{2}$ Royal National Hospital for Rheumatic Dieseases, Bath, United Kingdom; ${ }^{3}$ University of Bath, Department of Pharmacy and Pharmacology, Bath, United Kingdom

Background: Physical activity (PA) has been identified as a primary treatment option for people living with axial spondyloarthritis (axSpA) [1]. Yet, people living with axSpA can find it difficult to maintain PA at levels required to gain the evidenced benefits [2]. Intensive rehabilitation programmes harness the benefits of physical activity, but little is known about how to support PA maintenance when patients return to everyday life. The perspectives' of health professionals involved in rehabilitation programmes can provide important and rich insights into how people living with axSpA could be helped to maintain their PA.

Objectives: To explore health professionals' experiences of supporting PA maintenance during and after a rehabilitation programme for those living with axial spondyloarthritis.

Methods: A qualitative study was conducted using semi-structured interviews. Nine health professionals (i.e., 4 physiotherapists; 1 clinical nurse specialist; 1 rheumatology SpR; 1 psychologist; 1 occupational therapist; and 1 podiatrist) who contribute to a rehabilitation programme were recruited from the Royal National Hospital for Rheumatic Diseases in Bath, UK ( $M$ time contributing to course $=6.79 \mathrm{yrs}$, range $1-19.25 \mathrm{yrs}$; contact time over course range $=1$ to 45 hrs). Interviews were audio recorded, transcribed verbatim, and a thematic analysis employed [3].

Results: Maintaining a physically active lifestyle is a challenge for those living with axSpA and is an issue that is currently not being addressed. Health professionals' perspectives on supporting PA maintenance was illustrated through four main themes: (1) Social environment (group dynamic, importance of others with the same condition, immersion of the disease, external peer groups); (2) Re-framing (education, ownership, exercise off the pedestal, combating fear, routine and habit); (3) PA support (enjoyment and interest, PA as flexible, encouragement and importance, balance and realistic expectations, internal and external feedback); and (4) Challenges for health professionals (training, resources, knowledge of transition process to everyday life, difficulty motivating). The reasons why people engage in PA play a key role within each of these themes.

Conclusion: Results emphasize the current lack of support for the maintenance of PA and the complexities and challenges involved in maintaining PA for people living with axSpA. Interventions to support PA maintenance should pay particular attention to the importance of socially supportive environments, the need for enjoyment, and the use of internal and external feedback. The challenges faced by health professionals in motivating those living with axSpA to engage in PA regularly suggests a need for more training opportunities in motivation and health behaviour change.

References:

[1] Rausch Osthoff, A., Niedermann, K., Braun, J., et al., (2012) EULAR recommendations for physical activity in people with inflammatory arthritis and osteoarthritis. Annals of the Rheumatic Diseases, 77 (9), pp. 1251-60.

[2] McDonald, M. T., Siebert, S., Coulter, E. H., McDonald, D. A., and Paul, L. (2019) Level of adherence to prescribed exercise in spondyloarthritis and factors affecting this adherence: a systematic review. Rheumatology International, 39 (2), pp. 187-201.

[3] Braun, V., and Clarke, V. (2006) Using thematic analysis in psychology. Qualitative Research in Psychology, 3 (2), pp. 77-101.

Acknowledgments: The authors would like to thank the Bath Institute for Rheumatic Diseases (BIRD) and the University of Bath for funding the PhD studentship associated with this project

Disclosure of Interests: Thomas Ingram: None declared, Peter Rouse: None declared, Martyn Standage: None declared, Raj Sengupta Grant/research support from: Research grants from UCB, Pfizer, Abbvie and Novartis, Speakers bureau: Received honoraria for giving talks from Abbvie, Biogen, UCB, Novartis, Pfizer

DOI: 10.1136/annrheumdis-2020-eular.2782

\section{SAT0629-HPR FACTORS ASSOCIATED WITH USE OF BIOLOGICAL THERAPIES FOR AXIAL SPONDYLOARTHRITIS IN CANADA. RESULTS FROM THE IMAS SURVEY.}

R. Inman ${ }^{1}$, M. Garrido-Cumbrera ${ }^{2}$, J. Chan ${ }^{3}$, M. Cohen ${ }^{4}$, A. J. Debrum Fernandes $^{5}$, W. Gerhart ${ }^{6}$, N. Haroon ${ }^{1}$, A. Jovaisas ${ }^{7}$, G. Major ${ }^{8}$, M. Mallinson ${ }^{9}$, S. Rohekar ${ }^{10}$, P. Leclerc ${ }^{11}$, J. Schneiderman ${ }^{11}$, P. Rahman ${ }^{12}{ }^{1}$ TWH, Toronto, Canada; ${ }^{2}$ U. de Sevilla, Sevilla, Spain; ${ }^{3} \mathrm{UBC}$, Vancouver, Canada; ${ }^{4} \mathrm{MUHC}$, Montreal, Canada; ${ }^{5} \mathrm{U}$. de Sherbrooke, Sherbrooke, Canada; ${ }^{6} \mathrm{CSA}$, Phelpston, Canada; ${ }^{7} \mathrm{U}$. of Ottawa, Ottawa, Canada; ${ }^{8} \mathrm{CSA}$, Toronto, Canada; ${ }^{9}$ Patient, Toronto, Canada; ${ }^{10}$ Western U., London, Canada; ${ }^{11}$ Novartis, Montreal, Canada; ${ }^{12}$ Memorial U., St. John's, Canada

Background: Biologics have revolutionized the treatment of axial spondyloarthritis (axSpA). However, there is limited knowledge about factors associated with their use in Canada.

Objectives: To evaluate sociodemographic, healthcare and patient-reported outcomes (PROs) associated with the use of biologics in Canadian axSpA patients. Methods: The International Map of Axial Spondyloarthritis (IMAS) is a cross-sectional online survey of non-selected patients with self-reported axSpA, conducted in 21 countries and endorsed by the Axial Spondyloarthritis International Federation (ASIF). IMAS captures the patients' perspective of the burden of axSpA. The Canadian adaptation included a review of the survey by an advisory board of axSpA patients and a national steering committee composed of the Canadian Spondylitis Association, rheumatologists and patients. Participants were recruited between August 2018 and February 2019. Sociodemographic and healthcare-related variables, as well as PROs (disease activity [BASDAI, 0-10], spinal stiffness [3-12], functional limitation [0-54] and psychological distress [GHQ-12]) were collected. Respondents were divided in 2 groups 1) biologic and 2) NSAIDs or no treatment, based on reported pharmacologic treatments. Statistical analyses were performed to assess associations between variables and biologic use (bivariate) and the relative weight of these associations (multivariate). Results: 542 axSpA patients were recruited. Mean age was $44.3 \pm 13.9$ years, $63.1 \%$ were female, $66.4 \%$ married and $81.0 \%$ educated to university/college level. $22.8 \%$ of patients lived $>50 \mathrm{~km}$ from their rheumatologist. Mean BASDAl was $5.3 \pm 2.1$ and mean GHQ-12 score (mental health) was $4.0 \pm 3.8$. Nearly half $(49.6 \%)$ were currently on a biologic. Reported incidence of side effects was lower for patients having biologics $(42.5 \%)$ vs. a NSAIDs $(53.7 \%)$ as part of their treatment armamentarium. Only $15.7 \%$ of patients had discontinued biologic therapy, the main reasons for withdrawal being physician recommendation $(50 \%)$, side effects $(50 \%)$ and personal choice (34\%). Variables associated with biologic use included: membership of a patient support group $(p<0.001)$, non-manual work $(p=0.008)$, higher income level $(p=0.039)$, having a combination of public and private insurance schemes $(p<0.001)$ and diagnosis by a rheumatologist $(p<0.001)$. Associated PROs were spinal stiffness $(p=0.011)$ and diagnostic delay $(p=0.030)$. In the multivariate analysis, all variables except income and diagnostic delay were associated with biologic use (Table 1).

Table 1. Analysis of sociodemographic and clinical variables in relation to pharmacologic treatment

\begin{tabular}{|c|c|c|c|c|}
\hline \multirow[t]{2}{*}{ Variable } & \multicolumn{2}{|c|}{$\begin{array}{l}\text { Univariate linear } \\
\text { regression }\end{array}$} & \multicolumn{2}{|c|}{$\begin{array}{c}\text { Multivariate stepwise linear } \\
\text { regression }\end{array}$} \\
\hline & B & $95 \% \mathrm{Cl}$ & B & $95 \% \mathrm{Cl}$ \\
\hline Income level & 0.001 & $1.000-1.000$ & NA & NA \\
\hline Employment-manual worker & -0.761 & $0.266-0.822$ & -0.838 & $\begin{array}{c}0.228- \\
0.820\end{array}$ \\
\hline $\begin{array}{l}\text { Member of a patient support } \\
\text { group }\end{array}$ & 0.937 & $1.797-3.628$ & 1.116 & $1.754-5.309$ \\
\hline $\begin{array}{l}\text { Health insurance } \\
\text { scheme-combination }\end{array}$ & 0.209 & $1.162-1.307$ & 0.215 & $1.132-1.357$ \\
\hline Diagnostic delay & 0.009 & $0.993-1.026$ & NA & NA \\
\hline Spinal Stiffness (3-12) & 0.099 & $1.022-1.193$ & 0.220 & $1.090-1.424$ \\
\hline Diagnosed by rheumatologist & 0.535 & $1.412-2.067$ & 0.335 & $1.041-1.877$ \\
\hline
\end{tabular}

B, B coefficient; NA, [not applicable]

Conclusion: Canadian axSpA patients with greater social status, disease awareness, and insurance options are more likely to receive biologic therapy. Furthermore, Canadian physicians are more inclined to prescribe biologics to patients with increased spinal stiffness.

Disclosure of Interests: Robert Inman: None declared, Marco Garrido-Cumbrera None declared, Jon Chan: None declared, Martin Cohen: None declared, Artur J. deBrum Fernandes: None declared, Wendy Gerhart: None declared, Nigil Haroon: None declared, Algis Jovaisas: None declared, Gerald Major: None declared 
Michael Mallinson: None declared, Sherry Rohekar: None declared, Patrick Leclerc Employee of: Novartis, Julie Schneiderman Employee of: Novartis, Proton Rahman Grant/research support from: Janssen and Novartis, Consultant of: Abbott, AbbVie, Amgen, BMS, Celgene, Lilly, Janssen, Novartis, and Pfizer., Speakers bureau: Abbott, AbbVie, Amgen, BMS, Celgene, Lilly, Janssen, Novartis, Pfizer DOI: 10.1136/annrheumdis-2020-eular.4566

\section{SAT0630-HPR EFFECTS OF GOLIMUMAB ON WORK PRODUCTIVITY AMONG WORK-ACTIVE ANKYLOSING SPONDYLITIS NON-RADIOGRAPHIC AXIAL SPONDYLOARTHRITIS AND PSORIATIC ARTHRITIS PATIENTS IN GREECE: THE 'GO-UP' STUDY}

P. Athanassiou ${ }^{1}$, A. Kotrotsios ${ }^{2}$, I. Kallitsakis ${ }^{3}$, A. Bounas ${ }^{4}$, A. Garyfallos ${ }^{5}$, M. Tektonidou ${ }^{6}$, G. Vosvotekas ${ }^{7}$, E. Petrikkou ${ }^{8}$, G. Katsifis $^{9} .{ }^{1}$ Agios Pavlos General Hospital, Thessaloniki, Greece; ${ }^{2}$ Private Practice, Karditsa, Greece; ${ }^{3}$ Private Practice, Chania, Greece; ${ }^{4}$ Olympion Therapeutirion General Clinic, Patras, Greece; ${ }^{5}$ lppokrateion General Hospital, Thessaloniki, Greece; ${ }^{6}$ Laikon General Hospital, Athens, Greece; ${ }^{7}$ Euromedica General Clinic, Thessaloniki, Greece; ${ }^{8}$ MSD, Medical Affairs, Athens, Greece; ${ }^{9}$ Naval Hospital, Athens, Greece

Background: Golimumab is a tumor necrosis inhibitor (TNFi) approved for the treatment of axial SpA (axSpA) and psoriatic arthritis (PsA), both falling under the Spondyloarthritis $(\mathrm{SpA})$ domain. Real-world data regarding its effect on work productivity (WP) and activity impairment (Al) are limited

Objectives: To assess the impact of golimumab on WP and Al over 12 months of treatment in patients with SpA, overall, and in the axSpA and PsA subpopulations

Methods: A 12-month non-interventional, multicenter, prospective study performed in the routine clinical care. Data were collected at baseline (BL: prior to treatment onset), 3, 6 and 12 months. Adult work-active consented patients with axSpA [ankylosing spondylitis (AS) or non-radiographic axSpA (nr-axSpA)] or PsA, newly initiated on golimumab as per approved label, were concequetively enrolled by 20 sites. Patients prior in $>1$ biologic agent, or switched from another TNFi due to primary non-response or safety were excluded. WP and AI was assessed with the Work Productivity and Activity Impairment: Specific Health Problem (WPAl:SHP) instrument Results: Between Apr-2017 and May-2018, 121 (51: PsA, 70: axSpA) eligible patients (mean age: 45.4 years; $49.6 \%$ males; $69.0 \%$ overweight/obese; median disease duration: 11.3 months), (Figure 1), were enrolled. Median study duration participation: 11.9 months. Overall, $60.3 \%$ of the patients had previously received disease-modifying antirheumatic drugs and $16.5 \%$ biologics. At BL, the mean (standard deviation: SD) DAS28-ESR of the SpA population and PsA and axSpA subpopulations was 4.0 (1.3), 4.5 (1.2), and 3.6 (1.2), while the mean (SD) BASDAl score of patients with axSpA was 5.6 (1.9). At BL 94.1 and $96.7 \%$ of the SpA population reported WP loss and Al due to their SpA respectively, and at 3 months 87.3 , and $88.0 \%$ respectively. In SpA population, the median BL WP loss and AI were $70.0 \%$ and $65.0 \%$ and decreased by a median of $31.4 \%$ and $40.0 \%$ at 3 months, by $44.2 \%$ and $40.0 \%$ at 6 months and by $50.0 \%$ and $50.0 \%$ at 12 months, respectively (Table 1). Improvements in WP loss and Al were noted in patients with PsA, axSpA, AS and nr-axSpA (Table 1). 12-month golimumab retention rate: $91.7 \%$. No new safety signals emerged

Table 1. Decreases from BL at 3,6 and at 12 months in WP loss and overall Al with the WPAI:SHP instrument

\begin{tabular}{|c|c|c|c|c|c|c|}
\hline & \multicolumn{3}{|c|}{ WP loss (\%) } & \multicolumn{3}{|c|}{ Al (\%) } \\
\hline & \multicolumn{3}{|c|}{$\begin{array}{l}\text { Decrease from BL, } \\
\text { median }(n)\end{array}$} & \multicolumn{3}{|c|}{$\begin{array}{l}\text { Decrease from BL, } \\
\text { median }(n)\end{array}$} \\
\hline & 3 months & 6 months & 12 months & 3 months & 6 months & 12 months \\
\hline $\begin{array}{l}\text { Overall SpA } \\
\text { population }^{\mathrm{a}}\end{array}$ & $31.4^{a}(n=102)$ & $\begin{array}{l}44.2^{\mathrm{a}} \\
(\mathrm{n}=94)\end{array}$ & $\begin{array}{l}50.0^{\mathrm{a}} \\
(\mathrm{n}=87)\end{array}$ & $40.0^{a}(n=107)$ & $\begin{array}{c}40.0^{a} \\
(n=101)\end{array}$ & $\begin{array}{l}50.0^{\mathbf{a}} \\
(\mathrm{n}=92)\end{array}$ \\
\hline PsA & $31.4^{b}(n=46)$ & $51.4^{a}(n=42)$ & $\begin{array}{l}53.6^{a^{\prime}} \\
(n=40)\end{array}$ & $40.0^{a}(n=47)$ & $50.0^{a}(n=44)$ & $\begin{array}{l}60.0^{\mathrm{a}} \\
(\mathrm{n}=40)\end{array}$ \\
\hline axSpA & $33.0^{b}(n=56)$ & $\begin{array}{l}30.4^{\mathrm{b}} \\
(\mathrm{n}=52)\end{array}$ & $\begin{array}{c}45.5^{\mathrm{b}} \\
(\mathrm{n}=47)\end{array}$ & $40.0^{\mathrm{a}}(\mathrm{n}=60)$ & $40.0^{\mathrm{b}}(\mathrm{n}=57)$ & $\begin{array}{c}40.0^{\mathrm{b}} \\
(\mathrm{n}=52)\end{array}$ \\
\hline $\begin{array}{l}\mathrm{AS}^{\mathrm{c}} \\
\text { nr-axSpAc}\end{array}$ & $\begin{array}{l}25.1(n=35) \\
47.4(n=21)\end{array}$ & $\begin{array}{l}29.9(n=32) 3 \\
55.4(n=20) 5\end{array}$ & $\begin{array}{l}39.8(n=29) \\
53.2(n=18)\end{array}$ & $\begin{array}{l}20.0(n=39) \\
50.0(n=21)\end{array}$ & $\begin{array}{l}30.0(n=37) \\
55.0(n=20)\end{array}$ & $\begin{array}{l}30.0(n=34) \\
50.0(n=18)\end{array}$ \\
\hline
\end{tabular}

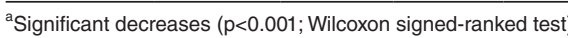

bignificant decreases $(p<0.001$; t-test)

'Statistical significance of the change from baseline was not examined due to the small observations' number

Conclusion: Patients in the SpA population and axSpA and PsA subpopulations treated with golimumab in a routine care setting experienced significant improvements in work productivity and daily activities at 3, 6 and 12 months after treatment initiation
Acknowledgments: The authors thank the following investigators: Ampatziadis E., Voulgari P., Gazi S., Georgiou P., Georgountzos A., Karokis D., Mpotzoris V., Mpournazos E., Sakkas L., Sidiropoulos P., and Vassilopoulos D. The study was Sponsored by MSD, Greece.

Disclosure of Interests: Panagiotis Athanassiou Grant/research support from: MSD, Genesis pharma, Janssen, Consultant of: Roche, Genesis pharma, Janssen, Speakers bureau: MSD, Janssen, Roche, Genesis pharma, Anastassios Kotrotsios Grant/research support from: MSD, Novartis, Roche, Consultant of: Bristol Myers Squibb, UCB pharma, Speakers bureau: Genesis pharma, UCB pharma, MSD Ioannis Kallitsakis Grant/research support from: MSD, Speakers bureau: Genesis pharma, Bristol-Myers Squibb, Andreas Bounas Grant/research support from: MSD,

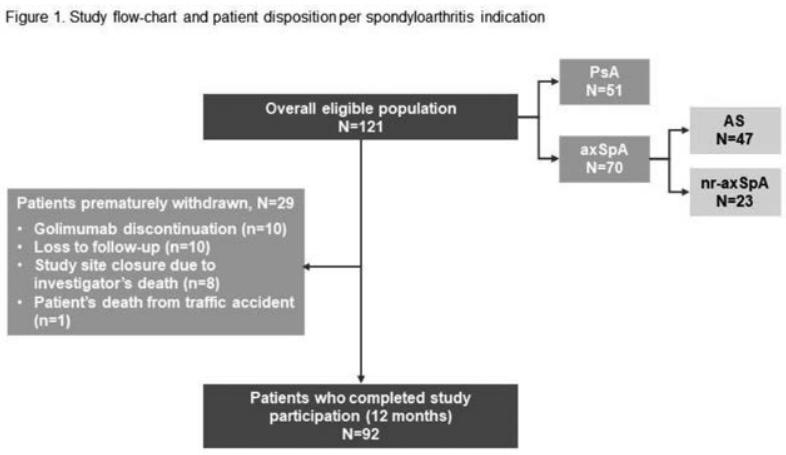

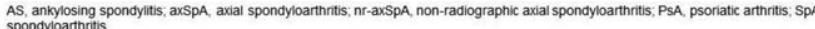

AbbVie, Novartis, Genesis pharma, Consultant of: MSD, Bristol-Myers Squibb, UCB pharma, AbbVie, Speakers bureau: MSD, Bristol-Myers Squibb, Pfizer, Alexandros Garyfallos Grant/research support from: MSD, Aenorasis SA, Speakers bureau: MSD, Novartis, gsk, Maria Tektonidou Grant/research support from: AbbVie, MSD Novartis and Pfizer, Consultant of: AbbVie, MSD, Novartis and Pfizer, GEORGIOS VOSVOTEKAS Grant/research support from: MSD, Janssen, Consultant of: MSD, Novartis, Roche, UCB pharma, Bristol-Myers Squibb, AbbVie, Speakers bureau: UCB pharma, Menarini, Bristol-Myers Squibb, MSD, Evangelia Petrikkou Employee of: MSD, Bristol Myers Squibb, Vianex SA, Gkikas Katsifis Grant/research support from: UCB Pharma, Janssen, Abbvie, Novartis, MSD, Aenorasis, Genesis Pharma, Pfizer, Roche, Consultant of: UCB Pharma, Janssen, Abbvie, Novartis, MSD, Aenorasis, Genesis Pharma, Pfizer, Roche, Speakers bureau: UCB Pharma, Janssen, Abbvie, Novartis, MSD, Aenorasis, Genesis Pharma, Pfizer, Roche DOI: 10.1136/annrheumdis-2020-eular.5572

\section{SAT0631-HPR WHEN CAN I STOP MY STEROIDS? THE PATIENT PERSPECTIVE ON GLUCOCORTICOID USAGE IN ADULT INFLAMMATORY MYOPATHY}

J. Loarce-Martos ${ }^{1}$, J. B. Lilleker ${ }^{2,3}$, E. Alder ${ }^{2}$, J. Goode ${ }^{4}$, H. Chinoy ${ }^{2,5} .{ }^{1}$ Ramón y Cajal University Hospital, Madrid, Spain; ${ }^{2}$ University of Manchester, Centre for Musculoskeletal Research, School of Biological Sciences, Faculty of Biology, Medicine and Health, Manchester Academic Health Science Centre, Manchester, United Kingdom; ${ }^{3}$ Salford Royal NHS Foundation Trust, Manchester Centre for Clinical Neuroscience, Manchester, United Kingdom ${ }^{4}$ Myositis UK, Southampton, United Kingdom; ${ }^{5}$ Salford Royal NHS Foundation Trust, Rheumatology department, Manchester, United Kingdom

Background: Glucocorticoids (GC) are long established as a first line treatment in patients with idiopathic inflammatory myopathy (IIM), in which high dose, long duration treatment is often required. GC usage is associated with a wide range of adverse effects (AEs). The patient perspective on the risks and benefits of GCs is not well studied and no prior studies assesses this issue in IIM patients (1). Objectives: To describe the perspective of IIM patients on GC treatment. Methods: We deployed an online survey distributed using the Myositis UK page on Healthunlocked.com, an online social network for health, with approximately 450 patients registered. Patients with diagnosed IIM were invited to take part on an anonymised basis. Respondents were asked to grade the severity on a Likert scale (1 to 5) of all AEs experienced in relation to GC. Additionally, respondents were asked to write about their concerns and to rate their overall experience with GC treatment. Results: In total, 122 completed surveys were received. Forty five percen (55/122) of respondents had dermatomyositis, $27 \%$ (33/122) polymyositis, $10 \%$ $(12 / 122)$ anti-synthetase syndrome, $18 \%(22 / 122)$ other inflammatory myopathies. Seventy-nine percent $(96 / 122)$ of respondents were female and the mean age overall was 50 years (SD [standard deviation] 14). 